\title{
Pohon Hanau dan Perempuan Siladang di Kampung Aek Banir
}

\author{
Hanau Tree and Siladang Women \\ at Kampung Aek Banir
}

\author{
Armansyah Matondang* \\ Program Studi Pemerintahan, Fakultas Ilmu Sosial dan Ilmu Politik \\ Universitas Medan Area, Indonesia
}

\begin{abstract}
Abstrak
Artikel ini menjelaskan dan memahami aktivitas perempuan Siladang dalam mengusahakan pohon Hanau di kampung Aek Banir". Pohon-pohon Enau merupakan sumber mata pencaharian utama (Primer) bagi penduduk Aek Banir yang di samping juga mengusahakan tanaman karet. Pohon enau juga merupakan sumber tambahan pendapat bagi penduduk Aek Banir juga tak jauh dari pemanfaatan keberadaan pohon Hanau (Enau), yaitu membuat sapu ijuk dan tali dari ijuk. Pohon Hanau diusahakan atau disadap bukan hanya oleh kaum laki-laki saja, tetapi perempuan di Aek Banir juga turut menjadi penyadap pohon Enau di Aek Banir memiliki jumlah yang tidak sedikit. Bahkan dengan sekilas saja, terlihat jumlah perempuan yang terlibah mengusahakan penyadap pohon Enau di Aek Banir memiliki jumlah yang tidak sedikit. Perempuan Aek Banir terkadang mengendong anak-anak mereka memanjat pohon-pohon Hanau ketika sedang menyadap maupun ketika hendak mengambil tuok (nira) hasil dari sadapan mayang-mayang Hanau.
\end{abstract}

Kata Kunci: Pohon Hanau, Perempuan Siladang, Kampung Aek Banir

\begin{abstract}
This article explains and understands the activities of the women of Siladang in cultivating the Hanau tree in the village of Aek Banir ". The Enau trees are the main source of livelihood (Primer) for the people of Aek Banir who in addition also work on rubber crops. The enau tree is also a source of additional opinions for Aek Banir residents also not far from the utilization of the Hanau tree (Enau), which is to make a palm fiber broom and rope from the fibers. Hanau trees are cultivated or tapped not only by men, but women in Aek Banir also become Ena's tappers in Aek Banir has a small amount. Even at a glance, it is seen that the number of women who are terrifly working on Enau tappers in Aek Banir has a small amount. Aek Banir women sometimes carry their children to climb the Hanau trees while they are tapping and when they want to take tuok (nira) from the lead of Hanau's head.
\end{abstract}

Keywords: Hanau Tree, Siladang Women, Kampung Aek Banir

How to Cite: Matondang, A., (2017). Pohon Hanau dan Perempuan Siladang di Kampung Aek Banir. JPPUMA: Jurnal Ilmu Pemerintahan dan Sosial Politik UMA, 5 (1): 1-8. 
Armansyah Matondang. Pohon Hanau dan Perempuan Siladang di Kampung Aek Banir.

\section{PENDAHULUAN}

"Au get maragat dope au amang....' Jadi inda bisa udokon amalan nai amang, Pula get di amang, sapai natobang-tobang i, Aturanna, i len kalai dei". (Saya masih mengambil nira nak... Jadi saya tidak dapat memberitahukan mantra-mantranya itu nak, Tapi kalau anak inginkan, dapat bertanya pada tetua-tetua itu, mereka akan memberikannya".

Pohon-pohon Enau atau Aren (arengga pinnata merr) dalam jumlah yang banyak berada di kan dan kiri sepanjang jalan ke arah kampung Aek Banir. Pohon Enau atau Aren, dalam bahasa silalang disebut sebagai Habau dan didalam bahasa Mandailing sebagai Bargot. Kekhasan itu semakin utuh ketika di tepian jalan terlihat perempuan-perempuan yang pulang atau menuju perladangan menyandang tagok di punggungnya, bahkan terkadang terlihat seorang perempuan menyandang empat tagok sekaligus, tagok adalah tempat penampungan nira yang berbuat dari bambu tagok dalam bahasa mandailing di sebut sebagai Garigit. Selain itu pemandangan yang lazim adalah perempuan-perempuan Aek Banir yang menjungjung kayu berukuran lumayan besar di atas kepala saat pulang dari kebun-kebun mereka, kayu tersebut nantinya akan di gunakan sebagai kayu bakar untuk keperluan memasak tuok (nira) atau untuk keperluan memasak di dapur. Dalam bahasa siladang nira yang bersumber dari pohon hanau yaitu ngiro. Air hasil sadapan dari pohon Hanau yaitu tuok merupakan bahan baku untuk pembuatan gula merah.

Kampung Aek Banir merupakan tempat penghasil gula merah yang tersohor di kabupaten Mandailing Natal, bahkan dapat dikatakan hasil-hasil produksi bernilai komersial yang berbahan baku dari pohon hanau merupakan ciri khas dari kampung Aek Banir (siladang). Kondisi ini yang berlangsung di atas, yakni keterlibatan perempuan di Aek Banir dengan lingkungan alam tempat mereka tinggal dapat disandarkan kepada pernyataan Rodda di dalam Laksono (2009:9), "secara tidak langsung, aktivitas perempuan berhubungan dengan pohon, tumbuhan dan hutan. Perempuan tradisional mengumpulkan produk dari tumbuhan dan tanaman-tanaman lainnya. Produk-produk tersebut memenuhi tiga kebutuhan dasar yaitu untuk bahan bakar, makanan, dan makanan ternak. Perempuan memandang hutan sebagai sumber kebutuhan dasar rumah tangga. Sedangkan kaum lelaki cenderung memandang hutan lebih aspek komersial".

\section{PEMBAHASAN}

Untuk menjelaskan keterlibatan perempuan dalam kegiatan menyadap pohon Hanau atau Enau di Aek Banir, merujuk kepada Maria Mies di dalam Laksono (2000:8), kegiatan perempuan dalam menyediakan pangan dinyatakan sebagai produksi kehidupan dan merupakan hubungan yang benar-benar produktif dengan alam. Antara alam dan perempuan bekerjasama sebagai mitra kerja yang mencciptakan hubungan khusus. Digambarkan oleh Mies bahwa interaksi perempuan dengan alam merupakan suatu proses timbal balik. Selanjutnya Rodda dalam Laksono (2000:7), tentang peranan perempuan dalam memenuhi kebutuhan rumah tangga dengan pemanfaatan lingkungan alam sekitarnya, sebagaimana diungkapkan berikut, di negara yang sedang berkembang, banyak perempuan yang berhubungan dengan lingkungan yang sangat vital untuk memenuhi kebutuhan hidup sehari-hari, misalnya pemenuhan air, kayu bakar, makanan, dan kebutuhan dasar lainnya. Perempuan tidak hanya mengawasi kerusakan lingkungan, tetapi juga memainkan peranan penting dalam mengelola lingkungan. Pun perempuan mampu mempengaruhi lingkungan dalam berbagai cara yaitu sebagai, consumers, campaigners, educatoors dan communicators".

Pohon Enau di kawasan pemukiman orang Siladang di Aek Banir bukan tumbuhan liar walaupun pepohonan 
tersebut tumbuh bukan karena dibudidayakan, tetapi tumbuh dikarenakan terkait dalam keberlangsungan mata rantai kehidupan. Walau begitu terdapat juga pohon-pohon Enau liar yang tidak dimiliki itu lazimnya terdapat di hutan-hutan yang tidak diusahakan, jauh di dasar dan tepian jurang-jurang atau ditepian sungai yang jauh dari kampung dan terlihat tidak diusahakan oleh orang lain. Perempuan Aek Banir (Siladang) dapat dikatakan dalam perjalanan siklus hidupnya tidak dapat dipisahkan dengan keberadaan pohon Hanau (Enau). Dengan rangkaian keseluruhan ungkapan di atas maka penulis ingin menyampaikan betapa vitalnya peranan pohon Hanau bagi perempuan di kampung Aek Banir (Siladang). Dikarenakan itu pula maka penulis memandang perlu menyajikan konsep kebudayaan sebagai landasan utuh buat penulisan penelitian ini. Yakni dengan memandang keberadaaan pohon Hanau sebagai titik pangkal untuk memasuki ranah kebudayaan yang dimiliki oleh orang Siladang pada umumnya, dan pada tulisan ini secara khusus akan memfokuskan pada persoalan untuk menjelaskan hubungan antara perempuan Siladang di Aek Banir dan pohon Hanau.

Salah satu konsep kebudayaan yang memiliki relevansi kuat dengan persoalan yang peneliti angkat dalam pandangan penulis adalah konsep kebudayaan yang disampaikan oleh Marvin Harris yang menyatakan bahwa kebudayaan merupakan sebagai suatu sistem, dan memiliki tiga subsistem dalam kebudayaan yakni : (1) subsistem teknik lingkungan (technoenvironmental) yaitu bagaimana manusia beradaptasi dengan lingkungan, memperoleh makanan, mengerahkan sumber daya yang dimiliki, menggunakan alat-alat, dan bagaimana mendistribusikan barang-barang itu; (2) subsistem ideologi (ideological) meliputi kepercaya-an, nilai, mitos, legenda, seni, musik, tari-tarian, dan semua komponen estetik kebudayaan; (3) dan subsistem sosio-politik (sociopolitical) yang melihat esensi hubungan antara individu dari satu kebudayaan dengan individu dari kebudayaan lain atau hubungan anatar satu individu dengan individu lain dalam suatu kebudayaan tertentu" Kessler dalam Laksono (2000:9).

Menurut Malinowski bahwa "fungsi kebudayaan untuk melayani kehidupan dan kelanjutan hidup. Setiap kebudayaan merupakan perangkat teknik untuk menyesuaikan diri dengan lingkungan yang dihadapi dengan orang lain. Kebudayaan menciptakan kebutuhan dan alat untuk memenuhi kebutuhan tersebut" Van Baal (dalam Laksono, 2000:9). Untuk memperkukuh landasan teoritis yang diangkat kali ini, maka penulis dalam menjelaskan perempuan Siladang di Aek Banir dan aktivitasnya dalam mengusahakan atau memanfaatkan pohon-pohon Hanau akan menyajikan pernyataan berikut, "pada setiap kebudayaan, perempuan dan laki-laki diberi peran dan pola tingkah laku yang berbeda untuk saling menghormati perbedaan kodrati dari kedua makhluk ini. Pembagian kerja secara seksual dengan begitu bersifat fungsional, artinya berguna bagi masyarakat secara keseluruhan (Laksono, 2000:9).

\section{Tahapan Malungkah Hanau (Menyadap Nira)}

Perempuan-perempuan siladang di Aek Banir sebelum malungkah Hanau terlebih dahulu melakukan persiapanpersiapan yang diperlukan. Persiapan yang mesti diselesaikan adalah menyiapkan perlengkapan-perlengkapan yang akan dibawa dan digunakan nantinya pada saat malungkah Hanau. Terdapat perbedaan persiapan malungkah Hanau pada pohon Hanau yang telah disadap dengan batang pohon Hanau yang baru akan pertama kali disadap atau akan diusahakan. Pada batang pohon Hanau yang baru pertama kali akan disadap atau diusahakan persiapannya terlebih dahulu disebutkan dengan sebutan "Mangalkali" oleh orang Siladang. Artinya sebatang pohon Hanau yang baru untuk pertama kalinya disadap 
Armansyah Matondang. Pohon Hanau dan Perempuan Siladang di Kampung Aek Banir.

maka persiapan sebelum sampai kepada pekerjaan malungkah Hanau dikatakan sebagai Mangalkali. Sedangkan untuk batang pohon Hanau yang telah diusahakan, disadap dan telah menghasilkan air nira atau tuok tersebut disebut dengan malungkah Hanau saja. Karena sebatang pohon Hanau yang telah menghasilkan air tuok kegiatan mangalkali telah selesai dilakukan padanya. Artinya tiap-tiap batang pohon Hanau yang telah disadap, aktivitas awal yang dilakukan atau perlakuan awal untuk mengusahakannya adalah mangalkali.

\section{Manga lkali}

Seperti disampaikan diatas mangalkali adalah suatu pekerjaan yang dilakukan untuk mempersiapkan alat-alat yang diperlukan untuk mengurus dan mengusahakan mengambil hasil (nira) dari sebatang pohon Hanau (Enau) yang belum pernah disadap atau yang baru untuk pertama kalinya akan diusahakan. Adapun persipan-persiapan yang harus diusahakan oleh seorang perempuan Siladang di Aek Banir pada saat hendak mangalkali, adalah menyiapkan alat-alat yang dibutuhkan, adapun alat-alat yang diperlukan tersebut adalah sebagai berikut:

\section{Mamuyu hejok (memintal ijuk),}

Pekerjaan ini adalah membuat tali dari bahan ijuk pohon Hanau dengan cara dipintal. Dibutuhkan dua orang pekerja untuk melakukannya. Pekerja pertama adalah pekerja utama, pekerja ini biasanya juga perempuan yang bisa juga memiliki kemampuan untuk malungkah Hanau. Sedangkan pekerja kedua dapat berupa seorang anak laki-laki berusia sekitar sepuluh tahun atau kurang, seorang gadis remaja, orang dewasa perempuan maupun laki-laki. Model atau cara pengerjaan mamuyu hejok (memintal ijuk) ini dapat diterangkan seperti berikut.

Pekerja pertama akan langsung duduk di atas tanah atau dengan memakai alas menghadap pada onggokan hejok (ijuk) dihadapannyadan dengan sebuah kayu kecil yang runcing dan memiliki kait kecil akan memulai menarik ijuk dihadapannya dengan satu tangan, sedangkan tangan yang sebelahnya akan mengirimkan ijuk yang ditarik ini kebelakang, dimana seorang pekerja lainnya memegang alat yang terbuat dari boloh (bambu) dan disebut dengan pangikubi ditangannya.

Putaran-putaran tersebut adalah gerakan tangan memutar atau melingkar agar ijuk yang dikirimkan kebelakang tertarik atau terpintal. Setelah tali semakin panjang terpintal maka ujungnya akan diikatkan pada sebuah alat yang disebut dengan sikusobi. Adapun sikusobi adalah sebuah bambu berukuran panjang sekitar setengah meter atau lebih sedikit yang pada bagian bawahnya runcing, bentuk runcing tersebut fungsinya adalah untuk menancapkan sikusobi ke tanah. dan pada sedikit dibawah ujung sebelah atas batang bambu dilubangi pada kedua sisinya dengan saling berhadap-hadapan dan padanya dimasukkan bambu berukuran kecil dengan panjang sekitar sejengkal tangan dan berbentuk letter T. Dan pada bambu berbentuk letter $\mathrm{T}$ itu diikatkan ijuk yang sudah berbentuk tali dengan panjang sekitar sejengkal pula.

Pada bagian sikusobi berbentuk letter $\mathrm{T}$ inilah tali ijuk yang sudah terpintal panjang ujungnya akan diikatkan oleh pekerja kedua. Dan pada saat akan mengikatkannya pekerja kedua yang bertugas memutar pangikubi akan menancapkan pangikubinya ke tanah, seperti diketahui alat pemutar yang berfungsi untuk memintal ijuk yang disebutkan diatas sebagai pangikubi juga yang ujungnya juga runcing. Adapun besaran tali hejok (ijuk) yang akan dipintal akan dibuat sesuai dengan kebutuhan yang diinginkan. Tali dari ijuk yang telah dipintal ini kegunaannya nanti adalah untuk mengikat sigai, tali penyandang tagok, pengikat tagok pada mayangan kafili ataupun pengikat mayangan kafili ke pelopoh (pelepah) Hanau atau ke mayangan kalto.

\section{Menyiapkan Sigai,}

Sigai adalah sebatang batang boloh (bambu) yang telah tua yang dijadikan sebagai alat atau tangga untuk memanjat 
pohon Hanau (Enau). Adapun bentuk Sigai adalah sebatang bambu yang seluruh ranting-ranting daunnya dibersihkan, dan pada tiap-tiap pertemuan ruas-ruasnya dimana terdapat buku-buku bambu, maka tepat diatas buku-buku tersebut dilubangi. Adapun lubang yang dibuat tepat di atas buku-buku bambu tersebut berfungsi sebgai anak tangga. Sigai yang telah dibuat akan disandarkan dengan cara diikat menggunakan tali hejok (ijuk) pada batang pohon Hanau yang akan disadap. Tali yang digunakan untuk mengikat sigai yang disandarkan pada batang Hanau sebaiknya adalah tali hejok, karena andaikan digunakan tali plastik dipastikan tidak akan berfungsi dengan baik dikarenakan licin. Kemudian untuk mendirikan dan menyandarkan sigai yang telah selesai dibuat itu biasanya diperlukan tenga sekitar tiga orang.

\section{Sandong atau parang}

Dalam bahasa Mandailing disebut dengan goluk, fungsinya adalah sebagai alat untuk malungkah Hanau (menyayat mayang kafili).

Gual (penokok), berguna sebagai alat penokok pada pangkal mayang kafili yang telah disayat.

Piso atau pisau berguna untuk membersihkan kulit yang terdapat pada mayang kafili yang telah disayat pada saat malungkah Hanau.

\section{Mangual-ngual}

Setelah tahapan mangalkali selesai dilakukan, maka tahapan selanjutnya adalah Mangual-ngual, yang dimaksudkan dengan Mangual-ngual adalah, mengayunayun mayang kafili dan menokok-nokok mayang tersebut pada posisi tertentu, dan yang terutama adalah pada ujung mayang kafili dimana tampolan (tebasan awal) untuk pertama kalinya telah dilakukan. Adapaun waktu yang dihabiskan untuk tahapan mangual-ngual tersebut adalah kurang lebih selama satu bulan.

\section{Manampol}

Tahapan manampol (tebasan pertama), adalah tahapan dimana mayangan kafili sudah tiba waktunya untuk disadap, adapun usia suatu mayang kafili Hanau dapat segera ditebas untuk pertama kalinya adalah pada saat berusia 50 hari. Adapun jumlah mayang kafili yang terdapat pada sebatang pohon Hanau maksimal 3 mayang. Mayang kafili dapat eneteskan air nira (berproduksi) selam beberapa bulan, namun jikalau bertemu dengan mayang yang baik, mayang tersebut dapat bertahan dan meneteskan air nira selama 1 tahun. Sekali lagi pada saat usia 50 hari itulah aktifitas manampol (tebasan awal) pada mayangan kafili harus segera dilakukan. Pada waktu atau tahap inilah seorang perempuan Siladang di Aek Banir akan membacakan amalan atau mantra yang dilikinya, yakni pada saat ia akan manampol atau tiap kali saat hendak malungkah mayang-mayang kafili. Ada dua jenis mayangan kafili yang ditemukan pada saat pertama kalinya ditebas (manampol):

Mayang kafili Hanau yang ditebas (manampol) buat pertama kali itu langsung terlihat berair pada permukaan mayang yang ditebas. Maka mayang kafili seperti ini adalah mayang kafili yang akan segera dapat menghasilkan tuok (nira). Terhadap mayang kafili seperti ini hanya diperlukan waktu (ditunggu) sekitar tiga hari, maka mayang ini akan didapati mengeluarkan (meneteskan) nira.

Mayang kafili Hanau yang ditebas (manampol) buat pertama kali tersebuttidak langsung terlihat berair pada permukaan mayang yang ditebas. Untuk menangani mayangkafili berjenis ini maka ditunggu waktu selama satu bulan. Waktu satu bulan tersebut adalah untuk menuakan mayang kafili yang belum mengeluarkan air itu. Dan sebagai pertanda mayang kafili akan mengeluarkan air, maka pada mayang itu akan terlihat pertanda jikalau akan segera berair. Adapun tanda tersebut adalah pada mayang yang ditebas itu nampak didatangi jenis binatang seperti loboh (lebah), naneng (naning), lalak (lalat) dan kulakkulak (ulat-ulat). Dengan adanya tandatanda tersebut biasanya air nira akan segera tiba (menetes). 
Armansyah Matondang. Pohon Hanau dan Perempuan Siladang di Kampung Aek Banir.

\section{Mambaba'bi}

Tahapan ini (mambaba'bi) adalah menyayat-nyayat sekaligus membersihkan kulit yang terdapat pada mayangan kafili yang telah ditebas untuk pertama kalnya (manampol) dengan menggunakan piso (pisau). Aktivitas ini adalah sebuah usaha yang dilakukan dan bertujuan agar air nira pada mayang kafili yang telah ditebas untuk pertama kali itu segera meneteskan tuok (air nira).

\section{Malungkah Hanau}

Tahapan ini merupakan puncak keseluruhan dari rangkaian tahapantahapan yang dilakukan oleh perempuan Siladang di Aek Banir untuk mendapatkan tuok (nira). Tahapan ini merupakan tahapan produksi. Dikatakan tahap produksi dikarenakan mayang-mayang kafili yang telah disayat tidak lagi memiliki halangan untuk meneteskan tetesantetesan air tuok. Tegasnya mayangan kafili telah berproduksi. Artinya seorang permpuan Siladang di Aek Banir tinggal melakukan rutinitas malungkah Hanau pada pagi dan sore hari. Adapun rincian daari aktifitas yang dilakukan seorang perempuan Siladang dalam malungkah Hanau adalah sebagai berikut: $a$. Berjalan sembari menyandang tagok, terkadang tagok yang disandang oleh seorang perempuan Siladang sampai empat tagok sekaligus menuju tempat batang pohon Hanau yang hendak diusahakan (disadap) tersebut berada. Jauh dekatnya suatu jarak harus ditempuh sesuai dengan dimana lokasi pohon Hanau yang hendak diusahakan berada.

Terkadang pohon Hanu yang hendak disadap berjarak dekat dan dapat diakses dengan kendaraan, batang-batang pohon Hanau seperti ini biasanya terdapat pada kebun-kebun penduduk Aek Banir yang berada didisi jalan raya. Tetapi adapula tempatnya yang jauh terletak di dalam hutan dan jurang-jurang pada pengaliran sungai Batang Gadis. Jarak inilah yang harus ditempuh oleh perempuanperempuan Siladang tersebut dengan berjalan kaki buat mencari nafkah keluarga. $b$, memanjat sigai dengan tagok tersandanng di punggung beserta perlengkapan lainnya melekat pada tubuh. $c$, memasang tagok pada mayang (kafili) dengan cara mengikatnya pada mayang kalto (buah enau) di atasnya atau pada polopoh (pelepah) Hanau dengan menggunakan tali ijuk. Kemudian mengambil tagok yang telah terisi atau yang dipasang pada saat malungkah sebelumnnya dan lalu menggantinya dengan tagok lainnya yang masih kosong. $d$, malungkah (menyayat) mayangan kafili sembari membaca amalan (mantra) yang dikuasai seorang perempuan Siladang pelungkah Hanau tersebut. $e$, kembali berjalan pulang ke rumah (Aek Banir).

\section{Memproduksi Gula Merah (Gula} Aren)

Tahap akhir dari pekerjaan malungkah Hanau bagi seorang perempuan Siladang di kampung Aek Banir adalah untuk memproduksi gula merah. Tujuannya adalah untuk mencari nafkah disamping suami untuk memenuhi kebutuhan dan keperluan keluarga atau sebagai sumber penghasilan keluarga. tegasnya, aktivitas malungkah Hanau merupakan sumber penghasilan pokok (primer) bagi sebagian keluarga di kampung Aek Banir. Dan penghasilan keluarga itu salah satunya didapatkan dari aktivitas para perempuan Siladang dengan cara malungkah Hanau dan membuat gula merah.

\section{1o. Memeseki Tuok (Memasak Nira)}

Setelah tagok-tagok (tabung) bambu berisi tuok (nira) diambil dan dibawa pulang ke rumah, maka tak lama kemudian pekerjaan selanjutnya dari perempuan-perempuan ini adalah memeseki tuok (memasak nira) yang akan dibuat menjadi gula merah (gula aren). Karena sebaiknya air nira yang telah diambil sebaiknya segera dimasak agar rasanya tidak berubah menjadi masam. Sebelum nira dituangkan ke kuali, maka tuok-tuok (nira) yang masih berada dalam tagok-tagok terlebih dahulu dicampur dengan akar aramambu yang telah ditumbuk, fungsi dari aramambu yang telah ditumbuk ini adalah untuk membuat 
tuok atau nira tidak menjadi masam. Namun andaikan akar aramambu tidak ada maka penngantinya dapat digunakan kulit dari batang pohon Manggis.

Namun dikatakan bahwa khasiat dari aramambu lebih baik dari kulit batang pohon Manggis. Memasak nira dilakukan dengan kayu bakar, dan kuali dijerangkan pada tiga buah batu yang berfungsi sebagai tungku. Pertanda nira sudah masak adalah terjadinya perubahan warna yang drastis yaitu warna berubah menjadi berwarna coklat tua kemerahan dan semakin lama semakin mengental. Kemudian waktu yang diperlukan untuk memasak nira menjadi gula merah adalah selama 5 sampai 6 jam. Adapun tungku ini berbentuk seperti segitiga, yang kalau tiap sisi batu ditarik dengan garis lalu disatukan. Kemudian di bawah tungku tersebut tanah digali seperlunya sebagai tempat untuk membakar kayu. Namun ada tungku memasak yang langsung menggunakan tanah yang digali sebagai tungku memasak. Pada model tungku seperti ini, permukaan tanah yang digali lebih dalam.

\section{Manuong \\ Mencetak)}

(Menuang atau

Setelah nira yang dimasak dianggap telah matang, maka pekerjaan selanjutnya adalah manuong (menuang) atau mencetak nira yang telah masak tersebut. langkah pencetakan gula merah terbilang sangat sederhana. Hanya memerlukan sebuah alat yang disebut sebagai sonduk (sendok). Alat ini terbuat dari tempurung kelapa berukuran besar dan bertangkai kayu. Kemudian terdapat sebuah sonduk yang berukuran kecil yang berfungsi sebagai sendok untuk memasukkan nira yang telah dimasak kedalam sonduk berukuran besar. Setelah sonduk besar penuh maka dari sonduk besar ini nira yang telah masak tersebutakan dituangkan ke sebuah wadah yang terbuat dari seng yang berbentuk lingkaran. Terdapat beberapa ukuran besar kecildari cetakan gula merah yang terbuat daari seng ini. Dahulu yang digunakan sebagai cetakan oleh orang-orang Aek Banir adalah cetakan yang menggunakan kulit bambu (boloh) sebagai alat cetakannyadan disebut dengan bilo. Bentuknya tetap sama yaitu berbentuk lingkaran. Hanya saja dikatakan cetakan dari kulit bambu ini hanya mampu mencetak gula merah berukuran kecil dan disebut oleh orang Siladang sebagai gulo nakacik atau gula kacik (gula kecil).

Disinilah letak peran penting perempuan-perempuan ini, yaitu kemampuan mereka memanfaatkan lingkungan dengan mengusahakan keberadaan batang-batang pohon Hanau ini sebagai sumber penghasilan keluarga. Dengan keterlibatan perempuanperempuan Siladang di Aek Banir dalam aktivitas malungkah Hanau (menyadap enau) maka dapat dikatakan bahwa perempuan Siladang memiliki produktifitas yang tidak kecil (significant) dalam membantu menopang atau memenuhi kebutuhan perekonomian keluarga. Seterusnya posisi perempuan Siladang ini selain dipandang dari segi produktivitas bernilai ekonomis, dan tak dapat dipungkiri kalau mereka juga memiliki etos kemandirian dalam bekerja seperti yang dilakukan oleh laki-laki Siladang.

Bahkan hanya itu saja, mereka juga memiliki pengetahuan, keahlian (skill) dan juga suatu ritus yang sakral seperti amalan (mantra) tertentu pada saat malungkah Hanau yang mesti dijaga kerahasiaannya. Maka berdasar kepada rangkaian di atas maka dapat dikatakan perempuan Siladang merupakan komunitas yang menyandarkan dirinya erat kepad alingkungan alam tempat mereka hidup dan mereka berperan penting dalam menopang kelangsungan hidup kelurga terutama dari segi aspek ekonomis, yang merupakan aspek penting dalam membangun keluarga yang harmonis dan memiliki masa depan. Dari itu semua dapat pula dikatakan kampung Aek Banir adalah ibarat suatu noktah dari kebudayaan palma raksasa yang melingkari seperempat garis bola Bumi ditengah manusia berkebudayaan sawah 
Armansyah Matondang. Pohon Hanau dan Perempuan Siladang di Kampung Aek Banir.

basah (weet rice farm) (Malik et all, 2003: 65).

\section{SIMPULAN}

Perempuan Siladang di Aek Banir sangat tergantung kepada lingkungan alam dimana mereka hidup dan tinggal. Aktifitas yang mereka lakukan walau terikat pada sifat kodrati yang mereka sandang sebagai perempuan, dimana bentuk realnya adalah sebagai ibu rumah tangga yang terikat dengan pekerjaan di dalam rumah, ternyata tidak menghalangi mereka untuk melakukan aktivitasaktivitas yang terkait erat dengan lingkungan alam ditempat mereka berada. Namun lingkungan alam tempat tinggal mereka yang khas telah menempa dan membentuk diri mereka untuk dapat menyesuaikan diri dengan alam sekitar mereka. Adapun bentuk penyesuaian tersebut adalah kemampuan mereka untuk memanfaatkan keberadaan lingkungan alam sekitar tempat mereka hidup untuk menopang dan memenuhi kebutuhan hidup keluarga. dan adapun penopang hidup mereka yang disediakan oleh lingkungan alam tempat mereka tinggal, salah satunya adalah keberadaan pohon-pohon Hanau (enau) yang banyak didapati pada bentang alam ditempat mereka tinggal.

\section{DAFTAR PUSTAKA}

Barth, Fredrick. 1988. Kelompok etnik dan Batasannya. Jakarta. UI Press

Harahap, Basyral Hamidi. 2004. Madina Membangun Masyarakat yang Madani, Suatu Studi Perbandingan. Jakarta: Metro Pos.

Ihoetan, Mangaradja. 1926. Riwajat Tanah Wakap Bangsa Mandailing di Sungai Mati Medan. Sjarikat Tapanoeli: Medan.

Koentjaraningrat. 1998. Pengantar Antropologi. Jakarta: Rineka Cipta

Laksono, PM., et.all,. 200o. Perempuan di Hutan Mngrove; Kearifan Ekologis Masyarakat Papua. Yogyakarta. PSAP UGM, Galang Press Yogyakarta dan Yayasan Kehati.

Malik, Ichsan\& Royo, Antoinette. 2003. Menyeimbangkan Kekuatan. Pilihan Strategi Menyelesaikan Konflik atas Sumber Daya Alam. Jakarta: Yayasan Kemala - United States Agency for International Development (USAID).

Reid, Anthony. 2011. Menuju Sejarah Sumatera. Jakarta. Penerbit Yayasa Obor Indonesia.

Said, Mohammad. Tanpa Tahun. Soetan Koemala Boelan (FLORA) Raja, Pemimpin Rakyat, Wartawan Penentang Kezaliman Belanda 1912-1932. Jakarta : UI Press

Spradley, James P. 1997. Metode Etnografi, Yogyakarta. Tiara Wacana Yogya. 